\title{
(RE) PENSANDO A EDUCAÇÃO INCLUSIVA: ANÁLISE CURRICULAR DE UM CURSO DE PEDAGOGIA
}

\section{(RE) THINKING INCLUSIVE EDUCATION: CURRICULAR ANALYSIS OF A PEDAGOGY COURSE}

\author{
(RE) PENSAMIENTO EDUCACIÓN INCLUSIVA: ANÁLISIS \\ CURRICULAR DE UN CURSO DE PEDAGOGÍA
}

\author{
Tatiany Michelle Gonçalves da Silva ${ }^{1}$ \\ tatyalmeidaesilva@gmail.com \\ Dirceu Manoel de Almeida Junior ${ }^{2}$ \\ dirceujunior2014@gmail.com \\ Rodrigo Francisco Dias ${ }^{3}$ \\ rodrigo.dias@ifmg.edu.br
}

\section{RESUMO}

Muito se tem discutido acerca do papel da educação inclusiva em nossas escolas, e a formação docente sobre essa perspectiva: Mendes (2006), Mantoan (2003; 2006; 2007), Demo (2017), Freire (1996; 2013), entre outros. Assim sendo, este trabalho de conclusão do curso de Especialização em Ensino Interdisciplinar em Infância e Direitos Humanos da Universidade Federal de Goiás/Regional de Catalão, que ao percurso de dois anos de muitas leituras voltadas à Inclusão, reforçou a nossa ideia de direito a educação, como sinônimo de igualdade e respeito à dignidade humana. Partindo desses princípios, propomos um novo olhar sobre a Educação Inclusiva, a partir da formação inicial dos pedagogos, de como são estruturadas as matrizes curriculares do curso de Pedagogia no que tange o tema inclusão. Neste caso, escolhemos o curso ofertado pela Universidade Estadual de Goiás na unidade de Formosa, no anseio de realizarmos a análise de como essa formação inicial tem contribuído para preparação desses docentes para a atuação na área inclusiva. Com efeito, o objetivo deste estudo foi analisar, por meio de uma pesquisa qualitativa de cunho documental, com a coleta de dados relacionados ao tema inclusão e usando como instrumentos: o Projeto Político desse curso de Pedagogia, os planos de ensino e as ementas de cada disciplina ofertadas pelo currículo atual, vigente desde 2015, para compreendermos se houve mudança especificamente no que concerne a inclusão escolar. Por fim, os resultados ressaltaram a complexidade do processo de implementação dessa temática no universo acadêmico e de como esse tema é abordado na formação inicial de Pedagogia do campus da Universidade Estadual de Goiás (UEG) de Formosa-GO.

\footnotetext{
1 Secretaria de Educação do Distrito Federal

2 Secretaria de Educação do Distrito Federal

3 Instituto Federal de Minas Gerais - Campus Bambuí
} 


\section{REVISTA @mbienteeducação}

SILVA, TMG; ALMEIDA JUNIOR, DM; DIAS, RF. (Re) pensando a educação inclusiva: análise curricular de um curso de pedagogia. Revista @ mbienteeducação. São Paulo: Universidade Cidade de São Paulo, v. 13, n. 2, p. 187-215 Mai/Ago 2020. PALAVRAS-CHAVE: FORMAÇÃO INICIAL; INCLUSÃO; CURRÍCULO DE
PEDAGOGIA.

\begin{abstract}
Much has been discussed about the role of inclusive education in our schools, and teacher training on this perspective: Mendes (2006), Mantoan (2003; 2006; 2007), Demo (2017), Freire (1996; 2013), among others . Therefore, this work to conclude the Specialization course in Interdisciplinary Teaching in Childhood and Human Rights at the Federal University of Goiás / Regional de Catalão, which over the course of two years of many readings focused on Inclusion, reinforced our idea of the right to education, as a synonym for equality and respect for human dignity. Based on these principles, we propose a new look at Inclusive Education, based on the initial training of pedagogues, on how the curricular matrices of the Pedagogy course are structured regarding the inclusion theme. In this case, we chose the course offered by the State University of Goiás at the Formosa unit, in the desire to carry out the analysis of how this initial training has contributed to the preparation of these teachers for working in the inclusive area. In fact, the objective of this study was to analyze, through qualitative research of documentary nature, with the collection of data related to the inclusion theme and using as instruments: the Political Project of this Pedagogy course, the teaching plans and the menus of each subject offered by the current curriculum, in force since 2015 , to understand if there was a change specifically with regard to school inclusion. Finally, the results highlighted the complexity of the process of implementing this theme in the academic universe and how this theme is addressed in the initial Pedagogy training of the campus of the State University of Goiás (UEG) of Formosa-GO.
\end{abstract}

KEYWORDS: INITIAL TRAINING; INCLUSION; Pedagogy Curriculum

\title{
RESUMEN
}

Mucho se ha discutido sobre el papel de la educación inclusiva en nuestras escuelas y la capacitación de docentes en esta perspectiva: Mendes (2006), Mantoan (2003; 2006; 2007), Demo (2017), Freire (1996; 2013), entre otros. . Por lo tanto, este trabajo concluyó el Curso de Especialización en Enseñanza Interdisciplinaria en Infancia y Derechos Humanos en la Universidad Federal de Goiás / Regional de Catalão, que, en el transcurso de dos años de muchas lecturas centradas en la inclusión, reforzó nuestra idea del derecho a la educación , como sinónimo de igualdad y respeto a la dignidad humana. Con base en estos principios, proponemos una nueva mirada a la Educación Inclusiva, basada en la capacitación inicial de los pedagogos, sobre cómo las matrices curriculares del curso de Pedagogía están estructuradas con respecto al tema de inclusión. En este caso, elegimos el curso ofrecido por la Universidad Estatal de Goiás en la unidad de Formosa, con el deseo de llevar a cabo el análisis 
de cómo esta capacitación inicial ha contribuido a la preparación de estos maestros para trabajar en el área inclusiva. De hecho, el objetivo de este estudio fue analizar, a través de la investigación cualitativa de naturaleza documental, con la recopilación de datos relacionados con el tema de inclusión y utilizando como instrumentos: el Proyecto Político de este curso de Pedagogía, los planes de enseñanza y los menús de cada asignatura ofrecida por el plan de estudios actual, vigente desde 2015, para comprender si hubo un cambio específico con respecto a la inclusión escolar. Finalmente, los resultados resaltaron la complejidad del proceso de implementación de este tema en el universo académico y cómo se aborda este tema en la capacitación inicial de Pedagogía del campus de la Universidad Estatal de Goiás (UEG) de Formosa-GO.

\section{PALABRAS CLAVE: ENTRENAMIENTO INICIAL; INCLUSIÓN CURRÍLO, PEDAGOGÍA}

\section{INTRODUÇÃO}

A proposta dessa pesquisa se apresenta em reexaminar a educação inclusiva, assim propomos um novo pensamento sobre a (trans) formação do pedagogo, por meio de sua formação inicial, proposta essa que chamamos de (re) pensar, já que esse é o intuito, de evidenciar a importância que esses futuros profissionais da educação tenham a práxis inclusiva como seu compromisso desde o começo de sua docência, formação que pode ser ofertada aos docentes desde seu percurso inicial formativo na Graduação.

Para consolidar nossas ideias iniciais, questionamos essa formação inicial e buscamos identificar se muitos dos prejuízos acadêmicos que vemos no meio educacional, em especial na área da educação inclusiva, vem da falta ou até mesmo do despreparo profissional decorrente da falha de preparo na formação inicial. Buscamos por meio desse instrumento acadêmico analisar as estruturas curriculares dessa formação, buscando entender como ela tem contribuído na preparação desses futuros profissionais para a sua atuação na educação inclusiva.

Apresentarmos nossas ideias e justificar se as mesma tem ou não uma justificativa correlata a formação inicial, iremos apresentar e perscrutar o currículo ofertado pelo curso de Pedagogia do campus da Universidade do estado de Goiás no município de Formosa, com o intuito de identificar como essa formação tem preparado seus pedagogos para atuação na área de educação inclusiva, já que esses profissionais formados por esse curso atuam nas redes educacionais municipais e estaduais públicas e também nas redes de ensino do Distrito Federal e do entorno.

Iniciamos nossa análise relativizamos a complexidade do tema e do entendimento que os docentes têm sobre as suas práticas na educação inclusiva, 
conhecimento esse que pode ser influenciado por questões tanto pessoais e quanto sociais para a sua construção individual. Por isso abordamos a importância do conhecimento da legislação que fundamenta essa prática no cotidiano escolar. $E$ nos questionamos: Como a formação inicial tem contribuído para a preparação dos pedagogos para o desenvolvimento de uma práxis inclusivas?

Para tanto, no intuito de obtermos a referida resposta, buscamos analisar o referido curso apontado por nós, inicialmente o seu PPCP-Projeto Político do Curso de Pedagogia, documento esse que fundamenta toda sua organização didáticopedagógica, o analisamos detalhadamente para entendermos como a temática da educação inclusiva tem se apresentado nas estruturas que fundamentam esse curso.

Como metodologia usamos a abordagem qualitativa - na qual não se tem a pressão de enumerar ou medir unidades ou categorias homogêneas, uma das maneiras que a pesquisa pode se caracterizar em qualitativa é "quando essa emprega como parâmetros ou critério avaliativo, categorias / escalas de atitudes, opinião, relatos ou até mesmo o comportamento" (OLIVEIRA, 2007, p.116). Para fundamentar nossas ideias usamos um amplo referencial teórico composto com autores como Mantoan, Demo e Mendes, que corroboram com sua descrição sobre a educação inclusiva e sobre o nosso sistema educacional, analises essas que auxiliam nosso debate sobre a importância da formação docente para educação, nesse caso, usamos a educação inclusiva para debater o quanto o processo de formação inicial ou continuada é necessária para a construção dessa modalidade de ensino.

$\mathrm{E}$, por fim, as considerações finais, aponta os resultados de nossas análises/ reflexões, nas quais constatamos como o processo formativo da graduação em Pedagogia do Campus de Formosa é organizado/estruturado, considerando as referidas matrizes Curriculares e ementas. Nesse sentido, apontamos, ainda, ações que poderiam ser realizadas e ampliadas, tendo por base questões referentes à matriz curricular, ofertas de atividades práticas no estágio supervisionado e em projetos de extensão que amplie a oferta da formação na área de inclusão nesse curso.

\section{ALGUMAS LEIS QUE REGULAMENTAM A INCLUSÃO}

Para iniciarmos nosso trabalho de pesquisa iremos elenca algumas leis que regulamentam a problemática que norteia a nossa proposta, que é formação docente para a prática inclusiva, para maior entendimento de como a educação inclusiva é assegura a nível nacionalmente pela legislação vigente tanto no sentido de assegurar condições de atendimento propícios a cada um dos descentes assim como de assegurar que seus docentes sejam formados/preparados desde a sua formação inicial para tal atribuição laboral. 
Essa proposta temática surge em parte da observação e vivência em ambientes escolares inclusivos, que nem sempre apresentam estar preparados ou equipados (infraestrutura) para realizar um processo formativo dos alunos público alvo da educação especial. Apontamos então leis que normatizam esse atendimento e garante acessibilidade a todos, assim como garante que esses educandos tenham professores formados para o ensino na área de educação inclusiva, que não recuem ao se depararem com os desafios da prática inclusiva e nem atribuíam essa omissão: a falta de formação, seja ela inicial ou continuada.

Para entendermos melhor essa formação inclusiva docentes que estamos falando iremos abordar a educação inclusiva sobre a ótica de autoras como Mendes (2006) que em sua obra "A radicalização do debate sobre a inclusão escolar no Brasil" aponta historicamente os erros e acertos da educação especial na prática escolar do nosso país e ao mesmo tempo define a importância da formação docente para essa atuação, formação essa que Matoan (2007) na sua obra "I gualdade e diferença nas escolas: olhares de futuras pedagogas" defende e explica a importância de que essa não seja mais uma ação preparo para a construção de regras de normatização de serviços de atendimento a inclusão na rede de ensino , que o docente possa ser (trans) formado nos espaços acadêmicos de forma que sua ação inclusiva seja repensada e que sua atuação possa garantir que esses educandos não sejam apenas "acomodados" nesses espaços escolares mas sim respeitados, valorizados e que seu intelecto assim quanto sua atuação social seja desenvolvida para que esse possa participação de forma plena e ampla de sua sociedade.

Algumas dessas normatizações no espaço escolar, são decorrentes da análise de algumas leis como : o artigo $\mathrm{n}^{\circ} 205$ da C.F- Constituição Federal Brasileira de 1988, que define que "A educação, direito de todos e dever do Estado e da família, será promovida e incentivada com a colaboração da sociedade, visando ao pleno desenvolvimento da pessoa, seu preparo para o exercício da cidadania e sua qualificação para o trabalho" algo que deve ser analisado pelo todo como direito de todos sem exceção que a mesma especifica a sua importância que é o pleno desenvolvimento do indivíduo para atuação em sua sociedade e na sua capacitação para o mercado de trabalho como forma de garantir igualdade de direitos a esses.

Para melhor entendimento desse dever do estado perante a "todos" o artigo $\mathrm{n}^{\circ} 208$ da mesma , em seu inciso III estabelece como dever do estado, "Atendimento educacional especializado aos portadores de deficiência, preferencialmente na rede regular de ensino", garantido assim além do entendimento previsto anteriormente a "todos" que pessoas com necessidades educacionais especiais sejam atendidas de forma plena e digna com respeito as suas condições: psicológicas e motoras para 
que a mesma possa ser preparada para sua atuação social , não de forma igualitária mas com equidade perante suas limitações.

Já a LBI - Lei Brasileira de Inclusão, incumbe ao poder público de assegurar, criar , desenvolver, implementar, incentivar, acompanhar e avaliar (artigo 28, p.07- 08); inciso I

sistema educacional inclusivo em todos os níveis e modalidades, bem como aprendizado ao longo de toda a vida, II- aprimoramento dos sistemas educacionais, visando a garantir condições de acesso, permanência , participação e aprendizagem , por meio da oferta de serviços e de recursos de acessibilidade que eliminem as barreiras e promova a inclusão plena, VI - pesquisa voltadas para o desenvolvimento de novos métodos e técnicas pedagógicas, de materiais didáticos, de equipamentos e de recursos de tecnologia assistiva e no inciso $X-a$ adoção de técnicas pedagógicas inclusivas pelos programas de formação inicial e continuada de professores e oferta de formação continuada para o atendimento educacional especializado (BRASIL, 2015).

Essas são algumas das legislações que norteiam as diretrizes de oferta de educação pública de alunos portadores de necessidades educacionais especiais das escolas públicas, claro que apontamos precisamente os incisos que certificam que sua escolarização tem como garantido a adequação curricular e metodológica assim como o preparo acadêmico de seu docente desde sua formação inicial, que tem por finalidade justificar a importância da nossa pesquisa dentro da formação inicial de docentes sobre a perspectiva da sua formação inclusiva, assim como de entender o quanto a regulamentação atual de nosso país contribui para a construção de uma formação tanto de discentes quanto de docentes dentro dessa perspectiva.

Algo essencial para a consolidação da oferta dessa modalidade de ensino assim como para a construção de práticas inclusivas é garantia que a sua matricula seja ofertada na rede regular de ensino, para que esse possa ter assim como todos os demais alunos da rede a oportunidade de desfruta da convivência de seus pares e da construção da qualidade de um ensino que o incluía no meio social, o que conforme Mariângela Graciano (2003) é um direito assegurado:

A realização do direito à educação não pode ser analisada apenas da perspectiva do acesso a vaga. $O$ direito refere-se à educação de qualidade e, este tema envolve múltiplas dimensões, entre elas, o papel da educação escolar na superação de preconceitos e desigualdades. (GRACIANO, 2003, p.201)

Que prepara o indivíduo para ter acesso ao seu meio social, que exigem que o estado/governo se construa uma infraestrutura que o ampare, que o profissional que atenda se capacite e que por fim que os cidadãos que com ele convive aprenda a respeitar os seus direitos. 
SILVA, TMG; ALMEIDA JUNIOR, DM; DIAS, RF. (Re) pensando a educação inclusiva: análise curricular de um curso de pedagogia. Revista @ mbienteeducação. São Paulo: Universidade Cidade de São Paulo, v. 13, n. 2, p. 187-215 Mai/Ago 2020.

Para o fortalecimento da efetividade dos artigos da C.F., em 1996 aconteceu o lançamento da LDB- Lei de Diretrizes e Bases da Educação ${ }^{4}$ em conjunto com o Decreto $\mathrm{N}^{0} 3.298^{5}$, onde ambos corroborarão com a criação de um currículo nacional de educação , que buscasse a inserção de pessoas com deficiências físicas, intelectuais, com transtornos de desenvolvimento global e de altas habilidades no ambientes escolares, sobre a perspectiva da oferta de um atendimento diferenciado e adequado a esse alunado, que tem como objetivo promovesse suas aprendizagens e seu desenvolvimento social e intelectual.

Não devemos deixar de citar, que também temos documentos internacional que norteiam a prática inclusiva dos educadores, legisladores e autores sobre a perspectiva da inclusão, um desses é a Declaração de Salamanca de 1994, que rege os princípios, políticas e práticas na área das Necessidades Educativas Especiais dentro do ambiente de ensino regular, ressalta a importância da estruturação do ensino em ação educação especial, que deve atender a todos em um espírito de respeito aos indivíduos e suas particularidades a partir das atribuições dos papéis do sistema escolar e de seus agentes que é o que nos interessa para nossa pesquisa . Dentre essas estão atribuições, descreve que:

\begin{abstract}
...toda criança possui características, interesses, habilidades e necessidades de aprendizagem que são únicas, sistemas educacionais deveriam ser designados e programas educacionais deveriam ser implementados no sentido de se levar em conta a vasta diversidade de tais características e necessidades... (DECLARAÇÃO DE SALAMANCA, 1994, p. 01)
\end{abstract}

Com esse análise buscamos, diretamente, compreender a legislação de base que fomenta o direito e o acesso desses educandos ao meio educacional, através da Declaração de Salamanca , pela Constituição Federal , pela LDB e por fim pela $\mathrm{LBI}$, regulamentação esse que buscam evidenciar que o atendimento a esses alunos não é apenas uma obrigação das atribuições laborais do docente e sim um direito constitucional, com isso se preparar (formação) para a realização do processo de escolarização desse alunado, vai além da boa vontade e afinidade com a área. Colocando o discurso da educação inclusiva no debate diário da vivência acadêmica e do meio educacional, sendo de certa forma radical como propõe a ação educativa defendida por Paulo Freire (2013).

4 LDB- Lei de Diretrizes e Bases da Educação, lei Nº 9.394 de 20 de dezembro de 1996, é a legislação que regulamenta o sistema educacional (público ou privado) do Brasil da educação básica ao ensino superior.

5 Decreto $n^{\circ} 3.298$, de 20 de dezembro de 1999, dispõe sobre a Política Nacional para a Integração da Pessoa Portadora de Deficiência, consolida as normas de proteção, e dá outras providências. 


\section{DIRETRIZES CURRICULARES NACIONAIS PARA OS CURSOS DE GRADUAÇÃO EM PEDAGOGIA DE 2006}

Já em concordância com o que diz Mantoan (2003), sobre a importância da formação docente para a consolidação da práxis inclusiva nas escolas, acreditamos também que a inclusão desses alunos nos meios educacionais não deve ser entendido pelo professor (a) como um ato de caridade e sim como uma concepção de uma atribuição profissional onde se é remunerado para tal e que a escolarização desse aluno não tenha apenas o papel de socializa-lo, com isso devemos evitar a cisão que ocorre, com o que os professores aprendem (teoricamente) e o que põe em prática nas salas de aulas.

Prática essa que muitas vezes é apenas condicionada a um sistema que cobra em excesso desses profissionais sem analisar a oferta que o mesmo tem de se capacitar, se preparar já que como veremos a diante dentro da perspectiva da educação inclusiva essa formação na graduação tem sido apenas mecanicista (DEMO, 2017) e essa tem diretamente influenciado o desempenho tanto de docentes quanto discentes, em ação linear e reprodutiva.

Então para a mudança drástica desse desempenho, que não tem se apresentado positivamente (IDEB, 2017), a formação do professor é algo valioso para que a inclusão aconteça efetivamente, que só a sua (trans) formação podem mudar a realidade atual da instituição escolar, que persiste em nortear suas ações por meio de um engenhoso sistema que mais classifica e rótula alunos com condições especiais de aprendizagem do que o inclui.

Por isso persistimos acreditando que é necessário (re) pensar a formação inicial, para atingirmos uma educação inclusiva que busque a garantia dos direitos negados a muito tempo a esses alunos, devemos buscar o entendimento que nada muda se não conhecermos as ferramentas para mudar e que ferramenta de professor é conhecimento, que deve ser rico e contínuo desde o momento que se inicia a sua formação/careira profissional até o último dia de sua regência (FREIRE, 2013)

Enfim, a escola, assim como o profissional que se propõe incluir, deve entender o papel da "inclusão" cabe mais que boa vontade e, que essa ação não é só o (re) conhecimento de que um novo público tem chegado a escola e que só sua "boa vontade" garantirá a eficiência de um trabalho educacional de qualidade a esses alunos. E sim a consciência que sua ação dependerá muito da sua formação que deve prepará-lo de forma ampla para o exercício atividade laboral reflexiva de atuação inclusiva. E que apenas conhecer a legislação vigente sobre o tema, não garante sua atuação e que no cotidiano escolar a teoria deve se conciliar com as ações práticas e assim formar a ação práxis inclusiva - ações pedagógicas nos princípios do respeito ao 
multiculturalismo próprio da sala de aula, da diversidade de gênero, etnia e crenças, formando assim uma educação inclusiva e democrática (OSÓRIO, 1999) , que não apenas utopicamente se espera, mas que é possível por meio da (trans)formação de nossos educadores. Algo que iremos abordar no capítulo seguinte através do tema da educação inclusiva e como a universidade, com foco a que escolhemos para nossa pesquisa tem se posicionado sobre a formação voltada a essa área da educação.

\section{ENTENDENDO A PRÁTICA DA EDUCAÇÃO INCLUSIVA}

Para se entender algo que requer uma observação e análise tão complexa, quanto a inclusão no cotidiano escolar, devemos explicar que a inclusão é uma questão que a própria Psicologia define como algo subjetivo, todos tem sua própria definição e interpretação pessoal sobre ela, tanto que para muitos a inclusão é um ato de caridade onde se deve incluir como um ato de generosidade apenas, para alguns profissionais da educação a escola regular não consegue nem atender as suas demandas diárias de seus alunos ditos normais então não deveria "incluir" e que isso apenas atribulação de suas funções, algo que nem o professor e nem a escola precisa ter: por isso eles defendem que lugar de aluno com condição diferenciada de ensino são em centros de ensino especializados é pronto! (MANTOAN, 2006).

Já para outros educadores, incluir é necessário e faz parte do processo que nos humaniza, nos dando a oportunidade de conviver com as diferenças é isso nos oportuniza crescimento e desenvolvimento pessoal (FERREIRA, 1993). No mesmo sentido a Declaração de Salamanca (1994, p. 19), articula que "a expressão necessidades educativas especiais referindo-se a todas as crianças e jovens cujas necessidades decorrem de sua capacidade ou de suas dificuldades de aprendizagem" podendo essa ser ou não mensurada, diagnosticada ou identificada. Reflexão essa que busca nos oportunizar o entendimento a nível acadêmico que responda o questionamento que norteia a nossa pesquisa, que é a importância da formação docente para a inclusão.

Deixando claro que nessa pesquisa não temos o foco de abordar a inclusão na prática de sala de aula e sim a formação dos nossos docentes para a construção das práticas de inclusão que temos hoje e que o nosso objetivo aqui é analisar a construção da práxis docente voltada a área de educação inclusiva, durante a formação inicial em Pedagogia dos acadêmicos em formação no campus universitário da Universidade Estadual de Goiás do município de Formosa-GO. Com o intuito de entender como essa formação inicial (graduação) tem contribuído teoricamente e na prática para a preparação desses futuros docentes, para a atuação em sala de aula inclusiva. 
Para isso analisaremos suas estruturas: matriciais e curriculares - que fundamentam a sua abordagem teórica da construção do conhecimento sobre a área inclusiva, utilizando o método de pesquisa scanning - pesquisa por palavras, através de uma pesquisa sobre termos conhecidos pela área de inclusão como: inclusão, inclusiva e incluir na sua ementa, nos conteúdos disciplinares e nas atividades complementares e extracurriculares, que nesse caso poderia ser o estágio supervisionado, buscamos por práticas curriculares descritas pelas diretrizes curriculares do curso que possam estabelecer a construção de uma atividade ampla entre teoria e prática em busca de uma formação completa dentro da área inclusiva (RAMOS, 2014).

\section{UEG CAMPUS FORMOSA - GOIÁS}

Mas, antes de iniciarmos o relato sobre a análise do PPCP do curso de Pedagogia, iremos apresentar o campus dessa instituição em Formosa e falaremos um pouco mais sobre o perfil descrito por esse documento do curso de Pedagogia, para depois analisarmos como tem ocorrido a formação desses acadêmicos de pedagogia na perspectiva da educação inclusiva.

O Campus da Universidade Estadual de Goiás em Formosa-GO, surge em 1999 através do decreto $n^{\circ} 5.158 / 9^{6}$, normativo esse do Estado de Goiás, que agrega algumas unidades acadêmicas distintas já existentes em uma só e a vincula a Secretária de Educação do Estado de Goiás, criando um polo no município de Formosa-GO, com o intuito de ampliar o ensino superior na região do entorno do Distrito Federal, com a oferta de cursos de licenciatura que possam oportunizar crescimento econômico ao município e entorno. Desde sua criação, a unidade desse pólo oferece seis cursos de licenciaturas: Geografia, Letra-Inglês, Matemática, Química, História e Pedagogia.

O curso de Pedagogia, que tem suas matrizes curriculares como objeto de estudo desse trabalho, iniciou sua oferta no ano de $2000 \mathrm{com}$ turmas de quarenta alunos que são ingressos em regime anual , com disciplinas semestrais, através de processo de seleção por vestibular, tendo um grande vínculo com a comunidade e respeito com a sociedade, o curso sempre busca atender tanto alunos do município quanto a alunos do DF e entorno, realizando com eles a integração social in loco na rede de ensino municipal, gerando assim um trabalho pedagógico em diversos locais como: empresas, hospitais e outros órgãos públicos. (PPCP, 2015, p.15).

6 Decreto $n^{\circ} 5.15,29$ de Dezembro de 1999, que vinculou organicamente a Universidade Estadual de Goiás à Secretária de Educação do Estado de Goiás. 
SILVA, TMG; ALMEIDA JUNIOR, DM; DIAS, RF. (Re) pensando a educação inclusiva: análise curricular de um curso de pedagogia. Revista @ mbienteeducação. São Paulo: Universidade Cidade de São Paulo, v. 13, n. 2, p. 187-215 Mai/Ago 2020.

No Projeto Político da graduação de Pedagogia, essa formação tem como justificativa da sua proposta de curso a preparação acadêmica de docentes para a atuação nas redes de ensino do Estado de Goiás e do Distrito Federal; exercendo a profissão de educador (Ibidem, p.14). E aponta como objetivos claros de sua estruturação, a formação convicta e motivadora para que o ensino seja de qualidade, voltado para a prática do dia a dia (Ibidem, p.16). Porém, na perspectiva da inclusão, que é abordada nesse trabalho, realizamos a pesquisa sobre a palavra INCLUSÃO nesse documento, que foi identificada apenas duas vezes, na página 33 com uma explicação da disciplina de: Educação Especial e Inclusão e na página 78 na grade curricular, abordando a disciplina anteriormente já citada na página 33.

Algo que nos chamou bastante atenção nesse documento e que o objetivo geral (pagina 16) apresentado pelo curso é de "Formar um profissional comprometido com a Educação e com seus educandos, com a autonomia intelectual, e a consciência crítica diante das inúmeras situações propostas na Rede Educacional" então a ação inclusiva deveria ser uma das prioridades dessa formação, já que a inclusão é um dos maiores desafios da educação atual (FIGUEIRA,2018), mas até essa página não identificamos nenhuma que cite esse ação pratica ou até mesmo formação teórica para esse desafio que é tão coetâneo e atemporal.

Ainda adiante, nesse mesmo documento é definido como papel de atuação desses futuros profissionais, nos objetivos específicos - que é do próprio pedagogo através dessa formação, ele seja um profissional inserido na contemporaneidade (Ibidem, p.17). E algo mais coetâneo que a educação inclusiva impossível, desde a última metade da década de 90 no campo educacional, desafio maior não há conforme Mendes (2006). Enfim, a compreensão contemporânea traz uma visão renovada baseada nos preceitos humanistas de que o homem deve ser respeitado com todas as suas limitações e dificuldades inclusive na área educacional (CORTELLA, 2015), com isso o que é proposto como objetivo do curso não se fundamenta com ações direcionada não chega as ementas e nem as matrizes curriculares, como veremos a diante.

No mesmo sentido, ao buscarmos a palavra inclusiva, descobrimos que desde 2013 a Universidade Estadual de Goiás tem aprovado pela resolução $\mathrm{n}^{\circ}$ 020/2013 a NAASLU - Núcleo de Acessibilidade Aprender Sem Limites - que estabelece a criação de grupos nas unidades de ensino para o atendimento a alunos de graduação portadores de necessidades educacionais especiais, mas no decorrer desse documento não identificamos nada mais que se relaciona-se a esse grupo da unidade de ensino de Formosa - GO e nem como se realiza esse atendimento nessa unidade acadêmica. 
Já para entender como funcionar a parte curricular do curso de Pedagogia, iremos dedicar o capítulo seguinte a essa análise, para o entendimento da organização didático-pedagógico que iremos perscrutar a estrutura curricular do curso de Pedagogia que está vigente desde 2015, no sentido de buscar conteúdos e autores apontados nas disciplinas que inicialmente identificamos como sendo da área de educação inclusiva ofertadas que são: Psicologia da Educação, Educação Especial e Inclusão e Libras- Língua Brasileira de Sinais.

Antes de fechar esse capítulo, apresentaremos uma das propostas de Projetos de extensão aplicados na unidade acadêmica de Formosa o Projeto GAIA - Observatório de Aprendizagens Inclusiva, que atende a comunidade acadêmica e externa do pólo desde 2014, essa formação é ofertada por uma professora efetiva do quadro docente da instituição, o projeto é ofertado nas dependências da unidade de ensino, em horário contrário das aulas de Pedagogia, compreende como uma formação de extensão não sendo obrigatória ou complementar a carga horária da formação inicial de Pedagogia, embora ele aborde a temática da inclusão é caracterizado como formação continuada. O GAIA tem uma carga horária de 180 horas, ministra conteúdos como: Inclusão no contexto escolar - LDB, Legislação, Leis e decretos; Deficiências Auditivas (DA), Deficiência Visual (DV), Deficiência Intelectual (DI), Deficiência Múltipla (DMU), Transtorno de Espectro Autista (TEA), Paralisia Cerebral (PC) e Altas Habilidades e superdotação, Síndromes e Necessidades Especiais de Aprendizagem (dislalia e dislexia).

Chamou-nos bastante a atenção, ainda, a abordagem metodológica aplicada no curso que é voltada a ação de pesquisa e prática, conciliada ao debate e depoimentos dos alunos. Uma experiência muito satisfatória e enriquecedora sobre a educação inclusiva e que tem visível sua busca de espaço e voz dentro dessa instituição de ensino, sendo esse o único projeto ou programa de extensão, que atende especificamente a questão da inclusão, dos atuais dezoitos projetos de extensão e complementação ofertado nos últimos nove anos na UEG/ Formosa-GO

\section{METODOLOGIA}

Como metodologia usamos a abordagem qualitativa - na qual não se tem a pressão de enumerar ou medir unidades ou categorias homogêneas, uma das maneiras que a pesquisa pode se caracterizar em qualitativa é "quando essa emprega como parâmetros ou critério avaliativo, categorias / escalas de atitudes, opinião, relatos ou até mesmo o comportamento" (OLIVEIRA, 2007, p.116).

Destarte, considerando a utilização de materiais impressos, usamos a pesquisa documental que, conforme a descreve Marconi e Lakatos (2010), caracteriza-se em 
trabalhar sobre fonte de dados restritos a documentos, os quais podem ser escritos ou não, denominando-se fontes primárias. Assim sendo, "a análise documental pode se constituir numa técnica valiosa de abordagem de dados qualitativos, seja complementando as informações obtidas por outras técnicas, seja desvelando aspectos novos de um tema ou problema" (LUDKE e ANDRÉ, 1986, p. 38).

Logo, usamos esse instrumento para auxiliar a nossa pesquisa, que se baseou na análise das matrizes curriculares dos cursos de Pedagogia ofertado pela unidade da UEG em Formosa-GO, analisamos as matrizes curriculares do ano de 2009 e a atual matriz em vigência estruturada em 2015, em conjunto com os planos de ensino (ementas) de cada disciplina, para termos um entendimento de como tem ocorrido a formação inicial sobre a perspectiva da educação inclusiva nesse curso. Curso esse que foi escolhido por formar profissionais/pedagogos que atendem nos órgãos educacionais do município e entorno, do Estado, do Distrito Federal e suas regiões administrativas.

Analisamos então cada disciplina que têm sua própria ementa - que é uma explicação da proposta de trabalho ofertada em cada uma, que pode ser entendida como plano de ensino de tem como função discriminar: o objetivo geral e os específicos, os procedimentos didáticos, as referências bibliográficas e as leituras complementares. Perscrutamos as Diretrizes Curriculares Nacionais Para os cursos de Graduação em Pedagogia de 2006 ementas das disciplinas que há uma correlação a área de inclusão, como citado anteriormente, para a identificação de conteúdo e indicação de autores relacionados a educação inclusiva, ação que identificamos ao realizarmos o uso do método de leitura SCANNING que segundo Lakatos é um tipo de leitura que busca “... um certo tópico da obra, utilizando o índice ou a leitura de algumas linhas, parágrafos , visando encontrar algumas palavras - chaves" ( Lakatos , 2014, p.20).

Aqui usamos as palavras-chaves: inclusão, inclusivo e incluir e obtivemos na grade curricular o destaque de quatro disciplinas que foram a de: Psicologia da Educação do $2^{\circ}$ período, da disciplina de Educação especial e inclusão no $3^{\circ}$ período, com a proposta de trabalho o respeito à diversidade como pressuposto ético essencial para a prática educativa. Educação escolar, democracia e inclusão (o seu plano de curso ${ }^{7}$ não se encontra disponível no site qual realizamos a pesquisa das demais disciplinas), atualmente essa é a uma das duas ofertas especifica de conteúdos voltados a área de educação inclusiva na proposta de oferta desse curso de Pedagogia, sendo a outra a disciplina de Libras-Língua Brasileira de Sinais do $4^{\circ}$

7 Site que se encontra os Planos de Ensino (ementa) do curso de Pedagogia da UEG/GO http://www.ueg. br/referencia/4974, impossibilitando assim sua análise e pôr fim a identificação se a mesma aborda a área de inclusão. 
período, que apresenta a historicidade da educação escolar dos surdos: aspectos legais e as tendências subjacentes à educação dos surdos.

No primeiro ano e do $5^{\circ}$ ao $8^{\circ}$ Período - que compreende do terceiro ao quarto ano, não identificamos nenhuma disciplina que aborde a temática da educação inclusiva de forma direta ou indireta qual pudéssemos considerar relevante ao nosso trabalho.

Ao analisarmos essa matriz curricular, observamos que essa tem a carga horária total de 3.340 horas/curso durante quatro anos e que dessas horas temos apenas 180 horas voltadas a Educação inclusiva, se consideramos a disciplina de Psicologia da Educação, ressaltando ainda que a disciplina de Libras também pode ser realizada na modalidade EAD (semi - presencial ou a distância). Contudo, essa matriz de 2015 tem apenas três disciplinas, que abordam sobre o ensino voltado a Educação Inclusiva, quais sejam: Psicologia da Educação, Educação Inclusiva e LIBRAS, todas essas com carga horária de 60 horas. Ficando evidente por essa matriz curricular que esse curso de Pedagogia não apresenta uma formação mais ampla na área da educação inclusiva, que a mesma atinge menos de $20 \%$ da carga horaria total do curso.

\section{PRÁTICAS DE UM SISTEMA INCLUSIVO}

A pergunta norteadora desse trabalho não é tão simples de se responde, como já vimos, já que buscamos entender os processos de formação de docentes na graduação para o atendimentos futuro de alunos com condições especiais de aprendizagem- os ANEE's, formação inicial essa que pode despertar um novo olhar dos profissionais da educação de que o papel de professor inclusivo não é apenas de socializar os alunos é sim de prepará-los para a vida social, respeitando as suas limitações e potencializando suas habilidades.

Para isso é necessário entender que o seu processo de "socialização" , no qual se pauta grande maioria das práticas de inclusão de muitos professores, deve ser entendido como um processo normal e corriqueiro que ocorre em todos os espaços onde esses alunos estão inseridos como em casa, em sua rua e nos outros espaços de atendimento de saúde, por isso devemos entender que o verdadeiro papel de atuação de professor na educação inclusiva é o de preparar/promover seus educando assim como se escolariza todos os seus demais alunos para que estes sejam inseridos nos meios sociais de forma igualitária (FIGUEIRA, 2018).

Para isso devemos ter em mente que a tarefa da escola e seus agentes, enfim de toda sociedade, deve se pautado na ação direta da construção de um sistema educacional que atenta a "todos" e seja feito para todos, dando espaço 
para a reflexão do conhecimento e do aprender com a diversidade, extinguindo os processos mecanizados de "aulas" , que vitimizam nossos educandos com a imposição da memorização, repetição e registro quantitativo para fim de avaliação de suas aprendizagens sendo algo que se perpétua e corrói todo nosso sistema escolar, sendo presente tanto na educação básica quanto na universidade (DEMO, 2016).

Para construirmos um sistema educacional que possa realmente se chamado de inclusivo, essas práticas devem ser abandonadas, se essas práticas do chamado sistema de aula não atendem nem os alunos ditos normais imagina os alunos que necessitam de condições de adequação curricular, de temporalidade e de ação metodologia alternativas? Já sabemos a resposta. Então por que não buscarmos uma ação (práxis) que atenda a todos, não só de forma igualitária, mas sim de forma completa, respeitando cada indivíduo como um único ser, valorizando suas potencialidades e habilidades, para que as práticas educacionais promovam sua vida e proporcione sua participação integral na sociedade.

Para se construir essa ação no cotidiano de nossas escola, devemos pensar em educação como estratégia de aprendizagem e de formação emancipatória de indivíduos, devemos ter hoje a meta de realizar uma educação inclusiva que gere autonomia e conhecimento a todos de forma integral e segundo Freire (1996) em sua obra Pedagogia da Autonomia o responsável direto dessa ação é o professor, mas como cobrar de alguém que promova uma ação de emancipação e de autonomia nas aprendizagens de seus educandos, se esse não teve em sua formação acadêmica/ profissional esses princípios despertados.

Por isso:

\begin{abstract}
A prática docente crítica, implicante do pensar certo, envolve o movimento dinâmico, dialético, entre o fazer e o pensar sobre o fazer. O saber que a prática docente espontânea, "desarmada", indiscutivelmente produz é um saber ingênuo, um saber de experiência e feito, a falta de rigorosidade metódica que caracteriza a curiosidade epistemológica do sujeito. Este não é o saber que o pensar certo procura. Por isso é fundamental que, na prática da formação docente, o aprendiz de educador assuma que o indispensável pensar certo não é presente dos deuses nem se acha nos guias de professores que iluminados intelectuais escrevem desde o centro do poder, mas, pelo contrário, o pensar certo que supera o ingênuo tem que ser produzido pelo próprio aprendiz em comunhão com o professor formador (FREIRE, 1996, p. 18).
\end{abstract}

Possibilitando assim ao educando em qualquer que seja a modalidade de ensino que se enquadre ou segmento que esteja, rompa as barreiras que impedem a construção do idealizado sistema educacional público brasileiro, onde não se aja exclusão, evasão e déficits baixos de aprendizagens. Onde o docente estabelece vínculos com seus discentes e faz da escolarização um meio de formação para a cidadania plena, algo que só pode ocorre através da reflexão do papel do professor no 
SILVA, TMG; ALMEIDA JUNIOR, DM; DIAS, RF. (Re) pensando a educação inclusiva: análise curricular de um curso de pedagogia. Revista @ mbienteeducação. São Paulo: Universidade Cidade de São Paulo, v. 13, n. 2, p. 187-215 Mai/Ago 2020.

processo inclusivo de todos, algo que com certeza pode começar desde a formação inicial deste docente e se aperfeiçoar ao longo de sua docência, rompendo com o atual sistema educacional que nos é apresentado.

Sistema esse que corrobora com as falhas que vitimiza a décadas as últimas gerações da classe baixa brasileira sendo esse um dos fatores de elitização do conhecimento e exclusão de muitos da rede de ensino, algo que se tornou tão evidente que em seu texto "Vítimas de Sala de Aula" o professor Pedro Demo (2016) realiza uma provocativa análise de como os futuros docentes são formados nas universidades para a atuação em sala de aula, aprendendo apenas reproduzir o que aprendeu, sendo esse mais uma vítima de um sistema de reprodução mecanizada de repasse de conteúdo, desde a sua formação inicial até a sua graduação, e isso é ele chama de sistema de "aula" e a esse sistema atribuí as falhas da nossa escolarização.

Mudar as nossas práticas é algo que parece ser meramente simples e comum, mas que na prática não é tão simples quanto parece, para isso devemos ter esse conhecimento, que é especifico como o letramento ou a alfabetização no bloco inicial, que requer horas de leitura e práticas já que não temos como saber o que vai ser ou não aproveitado desse conhecimento teórico na prática e que para se chegar a uma práxis devemos ampliar nosso conhecimento as ações metodológicas contextualizadas as interdisciplinaridades, para então rotularmos nossas ações de práxis inclusiva, lembrando que a cada aluno que atendemos essa deve se readaptar a suas particularidades até por que um laudo apenas aponta as suas limitações já identificadas mas não pode ser usado como um manual ao pé da letra, até por cada indivíduo é único e sua aprendizagem também.

Considerando tudo isso, podemos disser que muito temos caminhado para a construção desse sistema inclusivo em nosso país, que ao longo desses anos se tem avançado consideravelmente nessa área mas que muito ainda tem para ser realizado para a promoção da educação inclusiva no nosso sistema educacional. Que metas como proporcionar aos seus educandos o desenvolvimento da autonomia da construção de aprendizagem está ocorrendo, e que esses mesmos indivíduos estão cada vez mais sendo inseridos nesse processo inclusivo. As escolas brasileiras atualmente têm $57,8 \%$ de alunos com condições especiais de ensino segundo dados coletados no C.E - Censo Escolar de 2017, indivíduos esses que são classificados conforme sua especificidade, podendo esses terem laudos de deficiência intelectual, transtornos de desenvolvimento global e de altas habilidades, esses indivíduos podem estar divididos entre as modalidades de ensino regular da pré-escola até o Ensino Médio. Esse é apenas um dado que novamente reforça a importância da formação docente na área inclusiva, mas como fazer isso? Como prepara um professor para não apenas está na área de inclusão mas sim "ser" inclusivo. 


\title{
COMO SE PREPARA UM PROFESSOR PARA “SER” INCLUSIVO?
}

Ao longo da nossa vida acadêmica estamos em um processo constate de formação, buscando o conhecimento para então sermos habilitados para ser um docente por exemplo, um médico, um advogado, onde a formação dá a capacitação para o desempenho laboral de uma profissão. Mas a formação para "ser" um agente de inclusão na educação vai além dessa capacitação, não é apenas uma tarefa de habilitação, requer além do conhecimento teórico uma constante reflexão do papel do docente na vida desses educandos. Algo que parece ser normal, mas que não é tão simples. Junto à habilitação da docência todo professor tem um compromisso implícito de forma pessoas e essa tarefa requer uma reflexão constante desse profissional da sua atuação e do seu conhecimento, já que ele é a porta de acesso ao saber de muitos, mas ao se falar em processos de inclusão educacional de pessoas com necessidades educacionais especiais essa tarefa não pode se restringe apenas na escolarização desses alunos, sua prática deve ser embasada em uma ação que o leve da condição de estar na área de inclusão para ser um agente de inclusão, no sentido mais amplo da palavra inclusão que é ato ou efeito de incluir (- se). Com o intuito de que a:

\begin{abstract}
A educação inclusiva constitui um paradigma educacional fundamentado na concepção de direitos humanos, que conjuga igualdade e diferença como valores indissociáveis, e que avança em relação à ideia de equidade formal ao contextualizar as circunstâncias históricas da produção da exclusão dentro e fora da escola. (Política Nacional de Educação Especial na Perspectiva da Educação Inclusiva ${ }^{8}$ - MEC/SEESP, 2015, p.01)
\end{abstract}

Segundo essa concepção do MEC, a educação inclusiva é um dos paradigmas que atende a fundamentação dos direitos humanos nos meios educacionais, já que ela tem o intuito de promover a equidade de direitos a todos, ou seja, promover a garantia de legal a educação em todas as suas esferas e segmentos de forma igualitária. Para a garantia dessa realidade não podemos deixar de lembrar a importância do professor na tarefa diária de mediar a ação entre o que regulamenta a legislação sobre as práticas inclusivas com o que realmente chega aos alunos. Para que os profissionais da educação conheçam essas normatizações a atual legislação brasileira tem se buscado assegurar a garantia da formação de professores especializados para a área de ensino especial das escolas regulares, o que nem sempre chega a todos esses devido a oferta ser pouca de vagas desses cursos e nem todos os educadores

8 Política Nacional de Educação Especial na Perspectiva da Educação Inclusiva - Documento elaborado pelo Grupo de Trabalho nomeado pela Portaria Ministerial $n^{\circ} 555$, de 5 de junho de 2007, prorrogada pela Portaria $n^{\circ}$ 948, de 09 de outubro de 2007. 
SILVA, TMG; ALMEIDA JUNIOR, DM; DIAS, RF. (Re) pensando a educação inclusiva: análise curricular de um curso de pedagogia. Revista @ mbienteeducação. São Paulo: Universidade Cidade de São Paulo, v. 13, n. 2, p. 187-215 Mai/Ago 2020.

ter interesse em formações nessa área, algo que poderia ser amenizado ser esses tivessem essa formação desde sua habilitação inicial de graduação como exigência.

No entanto, há uma notória crise na formação nessa área, devido a extinção dos cursos de Pedagogia com habilitação específica a área de ensino especial e um quantitativo insuficiente de vagas em cursos de formação continuada como já citamos. Algo que muito nos preocupa e coloca em alerta sobre as dificuldades de se promover a formação / habilitação dos agentes da educação não apenas para atuarem nessa área e sim de "ser" inclusivo.

Ação que é tão sonhada e vemos a cada dia a dificuldade de sua prática efetivamente, durante a formação inicial temos ações isoladas de formação nessa área que são validadas pelas Diretrizes Curriculares Nacionais Para os cursos de Graduação em Pedagogia (2006) onde não se há especificado formação para o atendimento a alunos com condições especiais de ensino, tendo apenas algumas referências ao ensino voltado as "diversidades", o que pode ocorrer ao longo de um curso de quatro anos em uma única disciplina. Sendo a educação inclusiva, um dos temas tratados no curso de Pedagogia, apenas como um tópico para a formação do docente em licenciatura, sendo desconsiderada sua importância na formação docentes desses profissionais que irão preparar a formação dos alunos ANEE'S ao longo de toda sua vida docente.

Nessa perspectiva, Michels (2006) considera que a formação dos professores para estes seres inclusivo deve adquirir caráter prático e instrumental, com uma prática formatória destinadas a eles e a inclusão dos alunos que, historicamente, foram excluídos da escola e, que só a garantia da matrícula e frequência desses não determina a qualidade da formação oferta a eles, que há uma evidente distância entre o que rege a legislação da educação especial e as práticas que vemos em nossas escolas.

Com efeito, o autor antes mencionado ressalta que: sim, devemos atribuir ao professor essa tarefa de realiza a educação inclusiva, mas que o estado e a sociedade também têm um forte papel na execução dessa tarefa a de subsidiar as práticas de ensino com a garantia de formação e valorização de sua docência. Entendendo que ser "professor" inclusivo na atualidade e se assumir o compromisso profissional de buscar amenizar as práxis de décadas de exclusão desses alunos nas redes de ensino de nosso país.

Então a formação de um profissional da educação para a ser inclusivo deve ser um compromisso pessoal da sua profissão, da sua escola, da sociedade e de todos que têm uma visão que só as ações que oportunizem a equidade de direitos pode desenvolver o conhecimento e podem diminuir as diferenças, igualando as 
oportunidades que cada um deve ter como direito único dado pelo sociedade, pela escola e por todos que tem o privilégio de participar de sua formação.

Com base nessas atenuantes exposições de ideias, temos a fala dos autores Rinaldi, Reali e Costa (2007) sobre a atuação do professor, na qual os mesmos:

\begin{abstract}
Destacam que, partindo da premissa de que o professor deve assumir e saber lidar com a diversidade existente entre os alunos, em inúmeras pesquisas tem-se reafirmado a necessidade da melhoria da formação de professores como condição premente para a inclusão de pessoas com NEEs ${ }^{9}$. Tais pesquisas evidenciam que os professores, de maneira geral, não estão preparados para receber em suas salas de aulas alunos com NEEs. Um dos desafios que se tem para superar é a construção de um modelo de formação docente no qual a formação inicial ofereça ao futuro professor o conhecimento sobre a diversidade social, cultural e pessoal existente.(RINALDI, 2007, p. 8).
\end{abstract}

Por fim, as ideias acima corroboram com a nossa pesquisa sobre a importância da inserção de disciplinas que abordem a educação inclusiva e as práticas em ambientes que sejam inclusos, cursos complementares nas grades curriculares dos cursos de Pedagogia, que foquem na área de inclusão de forma obrigatória, para que o docente desde sua formação inicial já se sinta um professor inclusivo e, com isso, tenha o entendimento da importância da educação inclusiva assim que chegue as escolas e que seus cursos de capacitação na área inclusiva fossem como em todas as outras áreas da educação de aprimoramento e aperfeiçoamento de suas aprendizagens.

\title{
CONSIDERAÇÕES FINAIS
}

Iniciamos esse trabalho respaldando nossas reflexões em autores que comungam de nossas ideias, que partilham suas teorias sobre educação inclusiva e meios para se atingir a eficiência dos profissionais que atuam na área inclusiva desde sua formação inicial. Nesse sentido, analisamos os aspectos legais, que norteia a legislação nacional e internacional na perspectiva dos direitos sociais e educacionais de pessoas portadoras de necessidades educacionais especiais.

A partir do levantamento desse arcabouço teórico, da escolha da abordagem metodológica - pesquisa qualitativa, iniciamos a nossa pesquisa, que teve como intuito realizar a proposta de um novo pensar sobre a formação dos acadêmicos de Pedagogia sobre a área de educação inclusiva, no qual intitulamos de $(R e)$ pensando a educação inclusiva: análise curricular de um curso de Pedagogia.

9 NEE's - Necessidades Educacionais Especiais, assim são definidos os alunos com necessidade educacionais especiais por Rinaldi em sua obra "Educação especial e formação de professores: onde estamos ... para onde vamos? 
SILVA, TMG; ALMEIDA JUNIOR, DM; DIAS, RF. (Re) pensando a educação inclusiva: análise curricular de um curso de pedagogia. Revista @ mbienteeducação. São Paulo: Universidade Cidade de São Paulo, v. 13, n. 2, p. 187-215 Mai/Ago 2020.

Buscamos entender como o principal agente inclusivo- o professor, é preparação para atuação na educação inclusiva em sua formação inicial. E como essa formação tem contribuído para os equívocos das práxis desses educadores, o que contribui para exclusão de muitos discentes ao longo de suas vidas acadêmicas. Então escolhemos o curso de Pedagogia do campus da Universidade Estadual de Goiás no município de Formosa, com o intuito de entendermos melhor essa formação inicial, na perspectiva da atuação docente nas práticas inclusivas, de como esses futuros professores tem sido preparado para atender salas de aulas que tenha de um até quatro aluno com laudos diferenciados de comprometimentos psicológicos, psicossociais, motores e cognitivos. Essa escolha aconteceu devido essa formação anualmente capacitar três turmas de pedagogos (a), entorno de 120 alunos, para atuação direta em sala de aula e ser um dos cursos mais conhecidos do entorno do DF, o mesmo capacitou boa parte dos professores que estão em atuação tanto no município quanto no DF atualmente.

Após perscrutar sua documentação como: PPCP, ementas e grande curricular ficou evidente que ainda temos um longo caminho a percorrer dentro dessa modalidade de ensino de educação inclusiva na estruturação desse curso, identificamos que não há em sua composição uma atenção para a formação na área da inclusão em sua matriz curricular vigente, ao total de cinquenta e duas disciplinas temos apenas duas disciplinas que oferta essa formação - Educação Especial e Inclusão e Libras ${ }^{10}$ (oferta essa que ocorre por ser uma obrigação legal) o que totaliza 120 horas de formação teórica e mais a disciplina de Psicologia da Educação que aborda autores da inclusão com mais 60 horas de formação teórica, no mais nenhuma atividade que realize uma ação prática como a dos estágios ou algo similar. Com base na análise dessa matriz podemos concluir que está formação não estar muito longe ter uma carga horária compatível com a real necessidade de formação que a área inclusiva exige de nossos professores em nossas escolas e esse pode ser um dos motivos da construção apenas das práticas de acolhimento dada aos nossos educandos inclusivos no lugar de sua escolarização, sim a falta de formação desses educadores desde sua formação inicial pode sim impacta diretamente nas suas práticas/práxis ao longo de suas vidas docentes e com isso a perpetua ação de "aula" e apenas aula nunca será rompido.

Romper essas barreiras que insistem resistir em nossas escolas como um erro que não há solução o que é um grande equívoco podemos sim e devemos nos movimentar para mudar a realidade da oferta da inclusão na rede em ensino e para isso algo é muito importante a formação do professor que deve ser teoria e prática

10 Decreto $n^{\circ}$ 5.626, de 22 de Dezembro de 2005 - Que sanciona a inclusão das Libras - Língua Brasileira de Sinais, como disciplina curricular. 
para que esse seja conectado com a realidade de nossas escolas desde a sua formação e que com isso coloque em ação toda a teoria que tem debatido nos centros universitários , então ao falarmos da base teórica desse algo nos chamou a atenção ao analisamos os pressupostos teóricos que fundamentam as diretrizes desse curso identificamos que apenas a LDB foi abordada por que a LBI também não foi , pelo ou menos nas duas disciplinas inclusivas que é ofertada, o que contradiz o intuito exposto pela ementa que era de apresenta documentos que consolidassem esse direito legal dos deficientes.

Para entendermos melhor a construção dessas diretrizes buscamos 0 entendimento da articulação dos eixos, dos processos, das dimensões e dos princípios que estruturam/baseiam o curso de Pedagogia ofertado por essa unidade de ensino, identificamos no PPCP que o mesmo é norteado por ações didático-pedagógicas que se baseiam nos princípios de: a) pesquisa como princípio cognitivo e formativo; b) a integração entre teoria e pratica, ou seja, a práxis e c) a flexibilização (PPCP, 2015, p.68). Com isso usamos como base descritiva de nossa análise a identificação desses princípios ao longo desse documento sobre o a área de inclusão. Ressaltamos, a importância da base formativa dentro da temática abordada por esse documento que identifica a necessidade de uma educação aos portadores de necessidades especiais, mas não identificamos pesquisa e nem prática direcionada a ações de ensino na área da inclusão, nenhuma ação direta baseada em pressupostos teóricos para a fundamentação teórica de uma práxis inclusiva assim como não foi identificado nenhum método ou ação metodológica de ensino para a fundamentação de uma práxis inclusiva de seus acadêmicos.

Após essa analise podemos dizer que para melhor entendimento não se há o registro nesse e em nenhum outro documento analisado da exigência de atividade direcionada a área de inclusão, como: cursos complementares, práticas do estágio curricular e nem atividades de AEA - voltadas a essa temática. E que o projeto GAIA, que descrevemos no decurso deste texto, não é considerando como obrigatório e é ofertado pelo desejo de ampliação do conhecimento nessa área da professora que o ministra, não tem apoio evidenciado em nenhum dos documentos aqui pesquisado, o mesmo é apenas apresentado como uma extensão universitária aberta aos acadêmicos e comunidade externa.

Assim sendo, entendemos o quanto ainda é longa essa caminhada para conseguirmos efetivar o direito a "inclusão" dos educandos, despertando que essa reflexão não é apenas uma inquietação é sim a base para construção de proposta de trabalho que busca alertar a importância da formação inicial sobre a inclusão, não como apenas um direitos, mas como um dever do nosso sistema educacional, que tem provocado muitas mazelas na formação de toda uma geração , o que acreditamos 
não ser de forma intencional, mas por falta da intensidade desses debates nos meios acadêmicos, educacionais e sociais.

Debate esse que buscamos levantar ao propomos analisar essa problemática, tendo como objetivos gera a exposição de ideias e de alerta sobre a dificuldade que muitos professores ( pedagogos) tem de "ser" e atuar de forma inclusiva devida a carência de sua formação inicial, de capacitações com pouca qualidade, estudos isolados de grupos de debates, falta de prática na graduação (estágios específicos) e, por fim, a dificuldade de romper com as práticas rotineiras de um sistema educacional excludente como o nosso.

\section{REFERÊNCIAS}

BRASIL. Constituição Federal (1988). Constituição da República Federativa do Brasil. Brasília, DF: Senado Federal: Centro Gráfico,1988.

BRASIL. Lei n 13.146 de 06 de Julho de 2015- institui a Lei Brasileira de Inclusão da pessoa com Deficiência (estatuto da pessoa com deficiência). Disponível em: < http://www.planalto.gov.br/ccivil_03/_Ato2015-2018/2015/Lei/L13146.htm> acessado em 20 de Fevereiro de 2020.

BRASIL. Ministério da Educação. Censo Escolar de 2017- Portal INEP- Instituto de Nacional de Estudo e Pesquisas educacionais Anísio Teixeira. Disponível em: <http:// portal. inep.gov.br/web/guest/resultados-e-resumos > acessado em 10 de Abril de 2018.

BRASIL. Ministério da Educação. Declaração de Salamanca (1994). Disponível em: <http://portal.mec.gov.br/ seesp/arquivos/pdf/salamanca.pdf > acessado em 29 de Maio de 2018.

BRASIL. Ministério da Educação. Diretrizes Curriculares Nacionais para o Curso de Graduação em Pedagogia - Licenciatura. Disponível em <http://portal.mec.gov. br/cne/arquivos/pdf/rcp01_06.pdf > acessado em 10 de Novembro de 2018.

BRASIL, Ministério da Educação. Diretrizes Nacionais para a Educação Especial na Educação Básica / Secretária de Educação Especial - MEC; SEESP, 2001.

BRASIL. Ministério da Educação. Resolução $n^{\circ}$ 2, de 11 de Setembro de 2001Diretrizes Nacionais para a Educação Especial na Educação Básica. Disponível em: < http://portal.mec.gov.br/arquivos/pdf/resolucao2.pdf.> acesso em 09 de Maio de 2018 
BRASIL. Ministério da Educação. Decreto n 5.626, de 22 de Dezembro de 2005 - Inclusão da LIBRAS como disciplina curricular. Disponível em <http://www. planalto.gov.br/ccivil_03/_ato2004-2006/2005/decreto/d5626.htm > acessado em 23 de Maio de 2019

BRASIL. Ministério da Educação. IDEB - Índice de Desenvolvimento da Educação Básica. Disponível em <http://ideb.inep.gov.br/resultado/ > acessado em 12 de Março de 2019.

BRASIL, Ministério da Educação. Política Nacional de Educação Especial na Perspectiva da Educação Inclusiva - MEC/SEESP. Disponível em: < http:// portal.mec.gov.br/ index.php?option=com_docman\&view=download \&alias $=16690$ -politica-nacional-de educacao-especial-na-perspectiva-daeducacao-inclusiva05122014\&ltemid=30192> acessado em 12 de Janeiro de 2018.

BRASIL, Ministério da Educação. Resolução CsA n 891/2015 - Aprova o Projeto Pedagógico do curso de licenciatura - UEG campus Formosa e dá outras providências. Disponível em: < file:///C:/Users/TATIANE/Downloads/csa_2015_antigo_46_ novo_891.pdf > acessado em 24 de Maio de 2019.

COLETÂNEA CERIS. Ano 1, n.1 (2003) - Rio de Janeiro: CERIS/ Mauad, 2003. Direitos Humanos no Brasil: diagnóstico e perspectivas". Daniel Rech (coord.).

DEMO, Pedro. Questionando a graduação (ensaio). Disponível em <https://docs. google.com/document/d/1y-OhRklY-Lb_Y2P-0eVntZZQBY79MbPY4fSdA8T Sol 4/ pub > acessado em 10 de Agosto de 2017.

. Pesquisa qualitativa: Busca de equilíbrio entre forma e conteúdo. Revista latino-americana enfermagem, Ribeiro Preto, v. 6, n. 2, p. 89-104, abril 1998.

FERREIRA, Júlio Romero. A exclusão da diferença: a educação do portador de deficiência. Piracicaba: Unimep, 1993.

FIGUEIRA, Emilio. Educação Inclusiva - Ebook digital. São Paulo, 2018.

FREIRE, Paulo. À sombra desta mangueira / Paulo Freire; Ana Maria de Araújo Freire.11.ed.-Rio de Janeiro: Paz e Terra, 2013.

Pedagogia da autonomia. Saberes necessários à pratica educativa. Editora: Paz e Terra. São Paulo, 1996.

GAIA - Observatório de Aprendizagem de Inclusivas. Disponível em <http:// gaiaueg.blogspot.com/p/gaia-2019.html > acessado em 20 de Março de 2019. 
LAKATOS, Eva Maria. Metodologia do trabalho cientifico: procedimentos básicos, pesquisa bibliográfica, projetos, relatórios, publicações e trabalhos científicos / Mariana de Andrade Marconi , Eva Maria Lakatos. - 7.ed. - 9. reimpr. - São Paulo: Atlas , 2014.

MANTOAN, Maria Tereza Égler . Inclusão escolar: o que é? por quê? como fazer? / Maria Teresa Eglér Mantoan. — Editora: Moderna. São Paulo, 2003.

. PRIETO, Rosângela Gavioli; ARANTES, Valéria Amorim (Org.) - Inclusão escolar: pontos e contrapontos. Ed: Summus. São Paulo, 2006.

Igualdade e diferença nas escolas: olhares de futuras pedagogas. FE/ UNICAMP- Campinas, São Paulo, 2007.

MARCONI, Marina de Andrade; LAKATOS, Eva Maria. Fundamentos de Metodologia Científica. São Paulo: Editora Atlas S.A., 2010.

MENDES, Enicéia Gonçalves. A radicalização do debate sobre inclusão escolar no Brasil. Revista de Educação v.11 n.33 Set/Dez., 2006.

MICHELS, Mendes Helena, Gestão. Formação docente e inclusão: eixos da reforma educacional brasileira que atribuem contornos à organização escolar. REVISTA BRASILEIRA DE EDUCAÇÃO, Campinas, v. 11, n. 33, Set. /Dez. 2006.

MINAYO, Maria Cecília de Souza. Pesquisa Social: teoria, método e criatividade. Petrópolis, Vozes, 2012.

OLIVEIRA, Silvio Luiz de. Tratado de Metodologia Cientifica: projetos de pesquisas, TGI, TCC, monografias, dissertações e Teses; revisão Maria Aparecida Bessana. Editora: Thomson Learning. São Paulo, 2007.

OSÓRIO. Antônio Carlos do Nascimento. Projeto Pedagógico: o pensar e o fazer. Integração. Diversidade na educação. Brasília: ministério da Educação/Secretaria de Educação Especial. N. 21. P.11 - 18. $1^{\circ}$ semestre 1999.

RAMOS, Marise Nougueira. História e política da educação profissional. Curitiba, PR: Instituto Federal do Paraná, 2014. Disponível em: <http://curitiba.ifpr.edu.br/wpcontent/uploads/2016/Historia-e-politica-da-educação-profissiona.pdf>.

RINALDI, Renata Portela; REALI, Aline Maria de Maria Rodrigues; COSTA, Maria da Piedade. Educação especial e formação de professores: onde estamos... para onde vamos? Horizontes, Belo Horizonte, v. 25, n. 1, jan./jun. 2007 


\section{REVISTA @mbienteeducação}

SILVA, TMG; ALMEIDA JUNIOR, DM; DIAS, RF. (Re) pensando a educação inclusiva: análise curricular de um curso de pedagogia. Revista @ mbienteeducação. São Paulo: Universidade Cidade de São Paulo, v. 13, n. 2, p. 187-215 Mai/Ago 2020

\section{ANEXOS}

\begin{tabular}{|c|c|c|c|c|c|c|c|c|}
\hline \multicolumn{9}{|c|}{$\begin{array}{l}\text { Matriz de } 2015 \text { do curso de Pedage } \\
\text { Modalidade: licenciatura }\end{array}$} \\
\hline \multicolumn{9}{|c|}{ Integralização: mínimo 08 semestres e máximo 12 semestre } \\
\hline \multicolumn{9}{|c|}{ Carga horária total do curso: 3340 horas } \\
\hline \multicolumn{4}{|c|}{ Regime: seriado } & \multicolumn{5}{|c|}{ Início da Vigência: 2015} \\
\hline \multicolumn{4}{|c|}{ Turno: Conforme edital } & \multicolumn{5}{|c|}{ Vagas: Conforme edital } \\
\hline \multirow[b]{2}{*}{ Ano } & \multirow[b]{2}{*}{ Período } & \multirow[b]{2}{*}{$\begin{array}{l}\text { Componentes } \\
\text { Curriculares }\end{array}$} & \multirow[b]{2}{*}{ Núcleos } & \multirow[b]{2}{*}{ EAD } & \multicolumn{4}{|c|}{ Créditos } \\
\hline & & & & & créditos & $\begin{array}{l}\text { CHT } \\
\text { Teórico }\end{array}$ & $\begin{array}{c}\mathrm{CH} \\
\text { prática }\end{array}$ & $\begin{array}{l}\mathrm{CH} \\
\text { Total }\end{array}$ \\
\hline \multirow{14}{*}{$\begin{array}{c}1^{\circ} \\
\text { Ano }\end{array}$} & $1^{\circ}$ Período & $\begin{array}{l}\text { Linguagem, } \\
\text { Tecnologias e } \\
\text { Produção Textual }\end{array}$ & Comum & - & 04 & 60 & - & 60 \\
\hline & $1^{\circ}$ Período & $\begin{array}{l}\text { Metodologia } \\
\text { Cientifica }\end{array}$ & Modalidade & le & 04 & 60 & - & 60 \\
\hline & $1^{\circ}$ Período & $\begin{array}{l}\text { História da } \\
\text { Educação }\end{array}$ & Específico & - & 04 & 60 & - & 60 \\
\hline & $1^{\circ}$ Período & $\begin{array}{l}\text { Sociologia da } \\
\text { Educação }\end{array}$ & Específico & - & 04 & 60 & - & 60 \\
\hline & $1^{\circ}$ Período & $\begin{array}{l}\text { Educação e } \\
\text { Mídias }\end{array}$ & Específico & - & 04 & 60 & - & 60 \\
\hline & \multicolumn{4}{|c|}{ Carga Horária Total do Semestre } & 20 & 300 & - & 300 \\
\hline & $2^{\circ}$ Período & Arte e Educação & Específico & - & 04 & 50 & 10 & 60 \\
\hline & $2^{\circ}$ Período & $\begin{array}{l}\text { Psicologia da } \\
\text { Educação } \\
\end{array}$ & Modalidade & le & 04 & 60 & - & 60 \\
\hline & $2^{\circ}$ Período & $\begin{array}{l}\text { História Social da } \\
\text { criança e Infãncia }\end{array}$ & Específico & - & 04 & 60 & - & 60 \\
\hline & $2^{\circ}$ Período & $\begin{array}{l}\text { Práticas } \\
\text { Pedagógicas }\end{array}$ & Específico & - & 04 & 60 & - & 60 \\
\hline & $2^{\circ}$ Período & $\begin{array}{l}\text { Filosofia da } \\
\text { Educação }\end{array}$ & Específico & - & 04 & 60 & - & 60 \\
\hline & $2^{\circ}$ Período & Optativa I & Livre & - & 04 & 60 & - & 60 \\
\hline & \multicolumn{4}{|c|}{ Carga Horária Total do Semestre } & 24 & 350 & 10 & 360 \\
\hline & \multicolumn{4}{|c|}{ CARGA HORÁRIA TOTAL DO ANO } & 44 & 650 & 10 & 660 \\
\hline
\end{tabular}




\section{REVISTA @imbienteeducação}

SILVA, TMG; ALMEIDA JUNIOR, DM; DIAS, RF. (Re) pensando a educação inclusiva: análise curricular de um curso de pedagogia. Revista @ mbienteeducação. São Paulo: Universidade Cidade de São Paulo, v. 13, n. 2, p. 187-215 Mai/Ago 2020

\begin{tabular}{|c|c|c|c|c|c|c|c|c|}
\hline \multicolumn{9}{|c|}{ Matriz de 2015 do curso de Pedagogia da UEG - Campus Formosa GO. } \\
\hline \multicolumn{9}{|c|}{ Modalidade: licenciatura } \\
\hline \multicolumn{9}{|c|}{ Integralização: mínimo 08 semestres e máximo 12 semestre } \\
\hline \multicolumn{9}{|c|}{ Carga horária total do curso: 3340 horas } \\
\hline \multicolumn{4}{|c|}{ Regime: seriado } & \multicolumn{5}{|c|}{ Início da Vigência: 2015} \\
\hline \multicolumn{4}{|c|}{ Turno: Conforme edital } & \multicolumn{5}{|c|}{ Vagas: Conforme edital } \\
\hline \multirow[b]{2}{*}{ Ano } & \multirow[b]{2}{*}{ Período } & \multirow[b]{2}{*}{$\begin{array}{l}\text { Componentes } \\
\text { Curriculares }\end{array}$} & \multirow[b]{2}{*}{ Núcleos } & \multirow[b]{2}{*}{ EAD } & \multicolumn{4}{|c|}{ Créditos } \\
\hline & & & & & créditos & $\begin{array}{c}\text { CHT } \\
\text { Teórico }\end{array}$ & $\begin{array}{c}\mathrm{CH} \\
\text { prática }\end{array}$ & $\begin{array}{l}\mathrm{CH} \\
\text { Total }\end{array}$ \\
\hline \multirow{15}{*}{$\begin{array}{c}2^{\circ} \\
\text { Ano }\end{array}$} & $3^{\circ}$ Período & $\begin{array}{l}\text { Educação Especial e } \\
\text { Inclusão }\end{array}$ & Comum & - & 04 & 50 & 10 & 60 \\
\hline & $3^{\circ}$ Período & Literatura Infantil & Específico & - & 04 & 50 & 10 & 60 \\
\hline & $3^{\circ}$ Período & \begin{tabular}{|l|} 
Psicologia da \\
Educação - \\
Desenvolvimento e \\
aprendizagem
\end{tabular} & Específico & - & 04 & 50 & 10 & 60 \\
\hline & $3^{\circ}$ Período & $\begin{array}{l}\text { Aquisição e desenvolv. } \\
\text { da Linguagem }\end{array}$ & Específico & - & 04 & 50 & 10 & 60 \\
\hline & $3^{\circ}$ Período & $\begin{array}{l}\text { Bases epistemiologica } \\
\text { da Educação }\end{array}$ & Específico & - & 04 & 60 & - & 60 \\
\hline & $3^{\circ}$ Período & $\begin{array}{l}\text { Atividade de } \\
\text { enriquecimento e } \\
\text { de aprofundamento } \\
\text { ( AEA) - I ( } \\
\text { diversificada) }\end{array}$ & Específico & - & 04 & 60 & - & 60 \\
\hline & \multicolumn{4}{|c|}{ Carga Horária Total do Semestre } & 24 & 320 & 40 & 360 \\
\hline & $4^{\circ}$ Período & Teórias Pedagógicas & Específico & - & 04 & 50 & 10 & 60 \\
\hline & $4^{\circ}$ Período & Didática & Específico & - & 04 & 50 & 10 & 60 \\
\hline & $4^{\circ}$ Período & $\begin{array}{l}\text { Métodos e processos } \\
\text { de alfabetização e } \\
\text { letramento }\end{array}$ & Específico & - & 04 & 50 & 10 & 60 \\
\hline & $4^{\circ}$ Período & $\begin{array}{l}\text { Corpo, Cultura e } \\
\text { expressividade }\end{array}$ & Específico & - & 04 & 50 & 10 & 60 \\
\hline & $4^{\circ}$ Período & $\begin{array}{l}\text { Línguas brasileira de } \\
\text { sinais- LIBRAS }\end{array}$ & Específico & - & 04 & 50 & 10 & 60 \\
\hline & $4^{\circ}$ Período & Optativa II & Específico & - & 04 & 60 & - & 60 \\
\hline & \multicolumn{4}{|c|}{ Carga Horária Total do Semestre } & 24 & 310 & 50 & 360 \\
\hline & \multicolumn{4}{|c|}{ CARGA HORÁRIA TOTAL DO ANO } & 48 & 630 & 90 & 720 \\
\hline
\end{tabular}




\begin{tabular}{|c|c|c|c|c|c|c|c|c|}
\hline \multicolumn{9}{|c|}{ Matriz de 2015 do curso de Pedagogia da UEG - Campus Formosa GO. } \\
\hline \multicolumn{9}{|c|}{ Modalidade: licenciatura } \\
\hline \multicolumn{9}{|c|}{ Integralização: mínimo 08 semestres e máximo 12 semestre } \\
\hline \multicolumn{9}{|c|}{ Carga horária total do curso: 3340 horas } \\
\hline \multicolumn{4}{|c|}{ Regime: seriado } & \multicolumn{5}{|c|}{ Início da Vigência: 2015} \\
\hline \multicolumn{4}{|c|}{ Turno: Conforme edital } & \multicolumn{5}{|c|}{ Vagas: Conforme edital } \\
\hline \multirow[b]{2}{*}{ Ano } & \multirow[b]{2}{*}{ Período } & \multirow[b]{2}{*}{$\begin{array}{l}\text { Componentes } \\
\text { Curriculares }\end{array}$} & \multirow[b]{2}{*}{ Núcleos } & \multirow[b]{2}{*}{ EAD } & \multicolumn{4}{|c|}{ Créditos } \\
\hline & & & & & créditos & $\begin{array}{c}\text { CHT } \\
\text { Teórico }\end{array}$ & $\underset{\text { prática }}{\mathrm{CH}}$ & $\begin{array}{l}\mathrm{CH} \\
\text { Total }\end{array}$ \\
\hline \multirow{16}{*}{$\begin{array}{c}3^{\circ} \\
\text { Ano }\end{array}$} & $5^{\circ}$ Período & $\begin{array}{l}\text { Propostas Curriculares e } \\
\text { Metod. na Educação Infantil }\end{array}$ & Específico & - & 04 & 50 & 10 & 60 \\
\hline & $5^{\circ}$ Período & $\begin{array}{l}\text { Conteúdos e Processos } \\
\text { de ensino de Língua } \\
\text { Portuguesa }\end{array}$ & Específico & - & 04 & 50 & 10 & 60 \\
\hline & $5^{\circ}$ Período & Politicas Educacionais & Específico & - & 04 & 60 & - & 60 \\
\hline & $5^{\circ}$ Período & $\begin{array}{l}\text { Atividades de Orientação } \\
\text { em docência na Ed. Infantil I }\end{array}$ & Específico & - & 04 & 60 & - & 60 \\
\hline & $5^{\circ}$ Período & $\begin{array}{l}\text { Estágio Supervisionado em } \\
\text { Docência na Ed. Infantil I }\end{array}$ & Específico & - & 04 & - & - & 100 \\
\hline & $5^{\circ}$ Período & $\begin{array}{l}\text { Atividade de enriquecimento } \\
\text { e de aprofundamento ( AEA) } \\
\text { - II ( diversificada) }\end{array}$ & Específico & - & 04 & 60 & - & 60 \\
\hline & \multicolumn{4}{|c|}{ Carga Horária Total do Semestre } & 24 & 330 & 30 & 460 \\
\hline & $6^{\circ}$ Período & $\begin{array}{l}\text { Curriculos : Cultura escolar, } \\
\text { Politicas e práticas }\end{array}$ & Específico & - & 04 & 60 & - & 60 \\
\hline & $6^{\circ}$ Período & $\begin{array}{l}\text { Conteúdos e processo de } \\
\text { ensino de História }\end{array}$ & Específico & - & 04 & 50 & 10 & 60 \\
\hline & $6^{\circ}$ Período & $\begin{array}{l}\text { Conteúdos e processo de } \\
\text { ensino de Geografia }\end{array}$ & Específico & - & 04 & 50 & 10 & 60 \\
\hline & $6^{\circ}$ Período & $\begin{array}{l}\text { Atividade de orientação em } \\
\text { docência na Ed. Infantil II }\end{array}$ & Específico & - & 04 & 60 & - & 60 \\
\hline & $6^{\circ}$ Período & $\begin{array}{l}\text { Estágio Supervisionado em } \\
\text { docência na Ed. Infantil II }\end{array}$ & Específico & - & 04 & 60 & - & 100 \\
\hline & $6^{\circ}$ Período & $\begin{array}{l}\text { Métodos de produção } \\
\text { do trabalho cientifico em } \\
\text { Educação }\end{array}$ & Específico & & & & - & \\
\hline & $6^{\circ}$ Período & Optativa III & Livre & - & 04 & 60 & - & 60 \\
\hline & \multicolumn{4}{|c|}{ Carga Horária Total do Semestre } & 24 & 310 & 20 & 460 \\
\hline & \multicolumn{4}{|c|}{ CARGA HORÁRIA TOTAL DO ANO } & 48 & 670 & 50 & 920 \\
\hline
\end{tabular}




\section{REVISTA @mbienteeducação}

SILVA, TMG; ALMEIDA JUNIOR, DM; DIAS, RF. (Re) pensando a educação inclusiva: análise curricular de um curso de pedagogia. Revista @ mbienteeducação. São Paulo: Universidade Cidade de São Paulo, v. 13, n. 2, p. 187-215 Mai/Ago 2020

\begin{tabular}{|c|c|c|c|c|c|c|c|c|}
\hline \multicolumn{9}{|c|}{ Matriz de 2015 do curso de Pedagogia da UEG - Campus Formosa GO. } \\
\hline \multicolumn{9}{|c|}{ Modalidade: licenciatura } \\
\hline \multicolumn{9}{|c|}{ Integralização: mínimo 08 semestres e máximo 12 semestre } \\
\hline \multicolumn{9}{|c|}{ Carga horária total do curso: 3340 horas } \\
\hline \multicolumn{6}{|c|}{ Regime: seriado } & \multicolumn{3}{|c|}{ Início da Vigência: 2015} \\
\hline \multicolumn{6}{|c|}{ Turno: Conforme edital } & \multicolumn{3}{|c|}{ Vagas: Conforme edital } \\
\hline \multirow[b]{2}{*}{ Ano } & \multirow[b]{2}{*}{ Período } & \multirow{2}{*}{$\begin{array}{l}\text { Componentes } \\
\text { Curriculares }\end{array}$} & \multirow[b]{2}{*}{ Núcleos } & \multirow[b]{2}{*}{ EAD } & \multicolumn{4}{|c|}{ Créditos } \\
\hline & & & & & créditos & $\begin{array}{c}\text { CHT } \\
\text { Teórico }\end{array}$ & $\begin{array}{c}\mathrm{CH} \\
\text { prática }\end{array}$ & $\begin{array}{l}\mathrm{CH} \\
\text { Total }\end{array}$ \\
\hline \multirow{15}{*}{$\begin{array}{c}4^{\circ} \\
\text { Ano }\end{array}$} & $7^{\circ}$ Período & $\begin{array}{l}\text { Conteúdos e processos } \\
\text { de ensino de Ciências }\end{array}$ & Específico & - & 04 & 50 & 10 & 60 \\
\hline & $7^{\circ}$ Período & $\begin{array}{l}\text { Organização e Gestão } \\
\text { do trabalho Pedagógico }\end{array}$ & Específico & - & 04 & 50 & 10 & 60 \\
\hline & $7^{\circ}$ Período & $\begin{array}{l}\text { Atividade de } \\
\text { enriquecimento e de } \\
\text { aprofundamento ( AEA) } \\
\text { - III (diversificada) }\end{array}$ & Específico & - & 04 & 60 & - & 60 \\
\hline & $7^{\circ}$ Período & $\begin{array}{l}\text { Diversidade, cidadania e } \\
\text { Direito }\end{array}$ & Comum & - & 04 & 60 & - & 60 \\
\hline & $7^{\circ}$ Período & $\begin{array}{l}\text { Estágio Supervisionado } \\
\text { em Docência nos anos } \\
\text { iniciais I }\end{array}$ & Específico & - & 04 & - & - & 60 \\
\hline & $7^{\circ}$ Período & $\begin{array}{l}\text { Pesquisa e prática : } \\
\text { trabalho de curso I }\end{array}$ & Específico & - & 04 & 60 & - & 60 \\
\hline & \multicolumn{4}{|c|}{ Carga Horária Total do Semestre } & 24 & 330 & 30 & 460 \\
\hline & $8^{\circ}$ Período & $\begin{array}{l}\text { Financiamento e } \\
\text { Gestão dos recursos da } \\
\text { educação }\end{array}$ & Específico & - & 04 & 60 & - & 60 \\
\hline & $8^{\circ}$ Período & $\begin{array}{l}\text { Atividade de } \\
\text { enriquecimento e de } \\
\text { aprofundamento ( AEA) } \\
\text { - IV (diversificada) }\end{array}$ & Específico & - & 04 & 60 & - & 60 \\
\hline & $8^{\circ}$ Período & $\begin{array}{l}\text { Pedagogia em espaços } \\
\text { não escolares }\end{array}$ & Específico & - & 04 & 50 & 10 & 60 \\
\hline & $8^{\circ}$ Período & $\begin{array}{l}\text { Atividade de Orientação } \\
\text { em docência nos anos } \\
\text { iniciais II }\end{array}$ & Específico & - & 04 & 60 & - & 60 \\
\hline & $8^{\circ}$ Período & $\begin{array}{l}\text { Estágio Supervisionado } \\
\text { em docência nos anos } \\
\text { iniciais II }\end{array}$ & Específico & - & - & 60 & - & 100 \\
\hline & $8^{\circ}$ Período & $\begin{array}{l}\text { Pesquisa e prática : } \\
\text { trabalho de curso II }\end{array}$ & Específico & - & - & 50 & - & 50 \\
\hline & \multicolumn{4}{|c|}{ Carga Horária Total do Semestre } & 16 & 280 & 10 & 390 \\
\hline & \multicolumn{4}{|c|}{ CARGA HORÁRIA TOTAL DO ANO } & 36 & 600 & 50 & 840 \\
\hline
\end{tabular}




\section{REVISTA @mbienteeducação \]}

SILVA, TMG; ALMEIDA JUNIOR, DM; DIAS, RF. (Re) pensando a educação inclusiva: análise curricular de um curso de pedagogia. Revista @ mbienteeducação. São Paulo: Universidade Cidade de São Paulo, v. 13, n. 2, p. 187-215 Mai/Ago 2020.

\begin{tabular}{|c|c|c|}
\hline \multirow[b]{2}{*}{ Carga Horária de Atividades Formativas } & $\begin{array}{l}\text { Atividades } \\
\text { Complementares }\end{array}$ & 200 \\
\hline & $\begin{array}{l}\text { Demais } \\
\text { Componentes } \\
\text { Curriculares }\end{array}$ & 2640 \\
\hline Carga Horária de Atividades Teórico - Práticas & & 100 \\
\hline Carga Horária Total de Estágio Supervisionado & & 400 \\
\hline Carga Horária Total do Curso & & 3340 \\
\hline
\end{tabular}

\section{SOBRE OS AUTORES}

TATIANY MICHELLE GONÇALVES DA SILVA. Professora da Secretaria de Educação do Distrito Federal. Licenciada em Pedagogia e Biologia , especializada em Psicopedagogia, Orientação Educacional e em Ensino Interdisciplinar em Infância e Direitos Humanos; Mestranda em Ensino de Ciências Ambientais pela Universidade de Brasília.

DIRCEU MANOEL DE ALMEIDA JUNIOR. Professor da Secretaria de Educação do Distrito Federal; licenciado em Pedagogia e História pela IESA, Mestrando em Direitos Humanos, na Universidade de Brasília.

RODRIGO FRANCISCO DIAS. Professor da área de História do Instituto Federal de Minas Gerais/IFMG - Campus Bambuí; graduado em História (licenciado e bacharelado), Mestrado em História e Doutorado em História, pela Universidade Federal de Uberlândia (UFU).

RECEBIDO: 09/04/2020.

APROVADO: 29/04/2020. 